\title{
COMPORTAMENTO MECÂNICO DE PRECIPITADOS EM IMPLANTES DE QUADRIL FABRICADOS EM AÇO INOXIDÁVEL UNS S31675*
}

Claudio Teodoro dos Santos ${ }^{1}$ Ibrahim de Cerqueira Abud ${ }^{2}$ Maurício de Jesus Monteiro ${ }^{3}$ Jorge Arturo Hinostroza Medina ${ }^{4}$

Wellington Gilbert Fernandes ${ }^{5}$ leda Maria Vieira Caminha ${ }^{6}$

\section{Resumo}

O objetivo deste trabalho é avaliar o efeito da deformação elástica cíclica e da deformação plástica no comportamento mecânico dos precipitados presentes em um implante fabricado em aço inoxidável UNS S31675. O teste foi iniciado com carregamentos cíclicos e finalizado com carregamento contínuo de dobramento até a ruptura total do implante, no intuito de avaliar se os precipitados sofrem fratura e/ou decoesão da matriz. A flexão ocasionada pelo teste de fadiga resultou em zonas de tração nos lados lateral e posterior e compressão nos lados medial e anterior do implante. Após 6 milhões de ciclos ocorreu a fratura parcial do implante na aresta entre os lados lateral e posterior (zonas de tração). Os resultados mostraram a existência de estrias na superfície de fratura do implante, indicando que a fadiga foi o mecanismo de falha predominante. A análise microestrutural mostrou que os precipitados não fraturaram na região de falha por fadiga, mas sofreram fratura e decoesão na região submetida a deformação plástica por dobramento. Concluiu-se que, embora os precipitados sejam considerados sítios preferenciais para nucleação de trincas de fadiga, eles são capazes de suportar carregamentos cíclicos no regime elástico, mesmo com grau de flexão da haste, onde zonas de tração e compressão são criadas.

Palavras-chave: Implante de quadril; Aço inoxidável; Fase Z; Fadiga.

\section{MECHANICAL BEHAVIOR OF PRECIPITATES IN HIP IMPLANTS MANUFACTURED IN UNS S31675 STAINLESS STEEL}

\section{Abstract}

The aim of this study is to evaluate the effect of elastic and plastic deformation on the mechanical behavior of the precipitates present in an implant made of UNS S31675 stainless steel. The test was initiated with cyclic loading and finished with continuous bending load until the rupture, in order to evaluate if the precipitates undergo fracture and/or decohesion. The flexion caused by the fatigue test resulted in zones of traction on the lateral and posterior sides and compression on the medial and anterior sides of the implant. After 6 million cycles, fracture of the implant occurred at the edge between the lateral and posterior sides (traction zones). Results showed the existence of striations on the fracture surface, indicating that fatigue was the failure mechanism. Microstructural analysis showed that the precipitates did not fracture in the region of fatigue failure, but they undergone fracture and decohesion into the region submitted to plastic deformation by bending. It was concluded that, although precipitates are considered preferential sites for nucleation of fatigue cracks, they are able to withstand cyclic loading in the elastic regime, even with degree of flexion of the implant, where traction and compression zones are created.

Keywords: Hip implant; Stainless steel; Z-Phase; Fatigue. 
1 Engenheiro de Materiais, D.Sc., tecnologista, DIEMP, LACPM, Instituto Nacional de Tecnologia (INT), Rio de Janeiro, RJ, Brasil.

2 Engenheiro Metalúrgico, M.Sc., tecnologista, DIEMP, LACPM, Instituto Nacional de Tecnologia (INT), Rio de Janeiro, RJ, Brasil.

3 Engenheiro Mecânico, D.Sc., tecnologista, DIEMP, LACPM, Instituto Nacional de Tecnologia (INT), Rio de Janeiro, RJ, Brasil.

4 Engenheiro Mecânico, D.Sc., bolsista PCI, DIEMP, LACPM, Instituto Nacional de Tecnologia (INT), Rio de Janeiro, RJ, Brasil.

5 Técnico em Mecânica, técnico, DIEMP, LACPM, Instituto Nacional de Tecnologia (INT), Rio de Janeiro, RJ, Brasil.

6 Engenheira Metalúrgica, D.Sc., tecnologista, DIEMP, LACPM, Instituto Nacional de Tecnologia (INT), Rio de Janeiro, RJ, Brasil. 


\section{INTRODUÇÃO}

Nas últimas décadas, houve um aumento significativo no uso e demanda por implantes cirúrgicos devido ao aumento da população e do número de pessoas afetadas por acidentes e doenças.

Materiais metálicos biocompatíveis, tais como o aço inoxidável, o titânio e suas ligas e as ligas a base de cobalto, são usados em implantes que precisam suportar carregamentos mecânicos por longos períodos dentro do corpo humano. Este é o caso dos implantes de quadril, que para serem implantados precisam apresentar boa resistência mecânica, resistência à abrasão e à corrosão.

No Brasil, o implante de quadril mais usado é o de aço inoxidável, que foi escolhido pelo Sistema Único de Saúde (SUS) porque tem boas propriedades mecânicas, biocompatibilidade adequada e o menor custo quando comparado aos implantes fabricados de outros biomateriais metálicos (1). O aço inoxidável austenítico de designação UNS S31675 é o aço inoxidável AISI 316 modificado, contendo mais alto teor de nitrogênio e propriedades melhoradas para aplicações em implantes ortopédicos (Tabela 1). O nitrogênio causa um aumento da resistência mecânica e resistência à corrosão (2-4). A resistência mecânica aumenta por dois mecanismos neste aço: endurecimento por solução sólida da austenita e endurecimento por precipitação de nitretos ricos em nióbio, cromo e molibdênio (fase Z). Entretanto, os efeitos destes precipitados nas propriedades ainda não foram completamente compreendidos.

Tabela 1. Propriedades mecânicas dos aços inoxidáveis utilizados em implantes de quadril

\begin{tabular}{lll}
\hline Propriedade/Aço & AISI 316 (5) & UNS S31675 (6,7) \\
\hline$\sigma_{0,2 \%}(\mathrm{MPa})$ & 275 & 430 \\
\hline$\sigma_{\mathrm{r}}(\mathbf{M P a})$ & 630 & 740 \\
\hline $\mathbf{A L}(\%)$ & 42 & 35 \\
\hline Resistência à fadiga ao ar (MPa) & 276 & 587 \\
\hline Dureza Vickers (HV) & 168 & 244 \\
\hline
\end{tabular}

Propriedades do material recozido.

Giordani et al. (7) mostraram que muitos precipitados de fase $Z$ fraturaram quando corpos de prova padronizados de aço inoxidável UNS S31675 foram submetidos à testes de fadiga axial com carga máxima de tração acima do limite de escoamento do material. Este estudo mostrou que os precipitados são sítios preferenciais para a nucleação de trincas por fadiga quando ocorre a deformação plástica cíclica, contribuindo para diminuir a vida em fadiga deste aço. A fratura do precipitado geralmente ocorre quando a concentração de tensão ao redor do precipitado excede sua própria resistência, mas não a força coesiva matrizprecipitado. Assim, a descontinuidade geométrica associada à fratura se propaga instantaneamente através do precipitado e somente é interrompida quando alcança a matriz austenítica dúctil do outro lado do precipitado (7). O ambiente agressivo penetra na descontinuidade e entra em contato direto com o metal, promovendo a dissolução deste até que ocorra a sua repassivação (7). Além disso, a dissolução pode ser acelerada pela condição de deformação da matriz devido a concentração de tensão nas proximidades da descontinuidade. Giordano et al. (8) sugeriram que a precipitação da fase $Z$ leva à depleção de nitrogênio da matriz austenítica ao redor dos precipitados, o que poderia promover a corrosão localizada onde o nitrogênio não esta presente para proteger contra a corrosão. 
O objetivo do presente trabalho é avaliar o efeito da deformação elástica cíclica e da deformação plástica no comportamento mecânico dos precipitados num implante de quadril real (ao invés de corpos de prova padronizados) fabricado em aço inoxidável UNS S31675, utilizando para isso testes de fadiga e dobramento.

\section{MATERIAIS E MÉTODOS}

Neste trabalho, um implante de quadril modular (haste-cabeça) fabricado em aço UNS S31675 foi submetido ao carregamento cíclico no regime elástico (mais próximo ao do corpo humano) até sua falha. Posteriormente o mesmo implante foi submetido ao carregamento crescente em teste de dobramento até a ruptura completa no regime plástico, no intuito de avaliar a diferença de comportamento mecânico dos precipitados de fase $Z$ nos dois modos de carregamento. Embora sejam modos de solicitação muito diferentes, estes podem fornecer informações importantes sobre o comportamento mecânico dos precipitados existentes nestes aços. Mais detalhes sobre o implante e os procedimentos de teste serão fornecidos a seguir.

A Figura 1 mostra o implante de quadril utilizado neste estudo e a Tabela 2 apresenta as características técnicas deste implante. Nomes comerciais não serão apresentados neste trabalho, tendo em vista que o implante de quadril foi adquirido no mercado e não houve pedido de autorização ao fabricante.

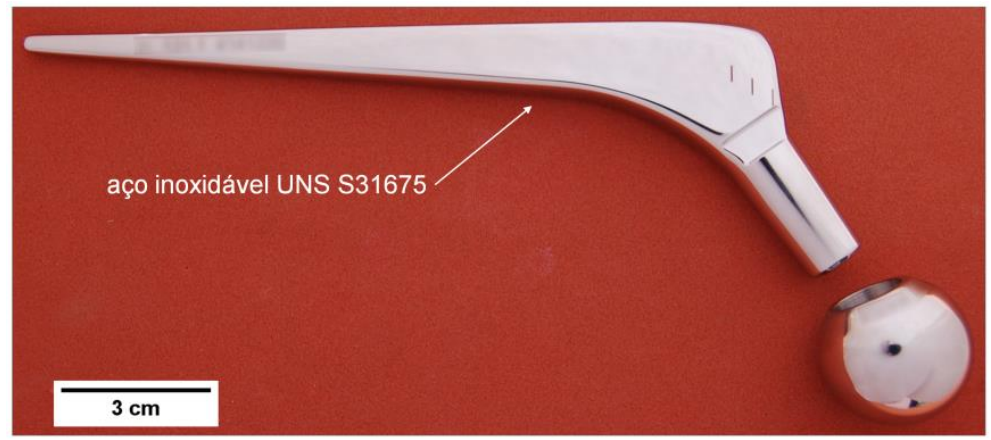

Figura 1. Implante de quadril de aço inoxidável.

Tabela 2. Características técnicas do implante de quadril utilizado neste estudo

\begin{tabular}{ll}
\hline Tipo & Cimentado \\
\hline Acabamento superficial da haste & Polida \\
\hline Comprimento da haste $(\mathbf{m m})$ & 150 \\
\hline Offset $(\mathbf{m m})$ & 37,5 \\
\hline Material da haste & Aço inoxidável austenítico \\
\hline Especificação & UNS S31675 \\
\hline Processo de fabricação & Forjamento a quente \\
\hline
\end{tabular}

No teste de fadiga, o implante de quadril foi inclinado e fixado de acordo com a configuração de montagem descrita na norma técnica ABNT NBR ISO 72064:2016 (Implantes para cirurgia - Próteses parcial e total de articulação de quadril Parte 4: Determinação de propriedades de resistência à fadiga e desempenho de componentes femorais com haste). Por outro lado, para o carregamento cíclico foram utilizados os parâmetros de teste e meio salino aquecido recomendados pela norma técnica ABNT NBR 15670-4:2009 (Implantes para ortopedia - Prótese ortopédica modular - Parte 4: Procedimento para ensaio de corrosão por atrito da interface da conexão cabeça-cone de próteses de quadri) por serem estes mais 
severos. Assim, o teste de fadiga realizado neste trabalho combinou as recomendações das normas de resistência à fadiga e corrosão por atrito, no intuito de produzir uma condição mais severa e assim reduzir a vida em fadiga do implante.

$O$ implante foi fixado em cimento ósseo (PMMA) da marca Baumer, com ângulos $\alpha=10^{\circ}$ e $\beta=9^{\circ}$ (conforme indicado na norma ABNT NBR ISO 7206-4, Anexo A), e nível de embutimento do implante no cimento mantendo a distância de 8 $\mathrm{cm}$ desde o centro da cabeça femoral até a superfície superior do cimento (fixação distal), conforme mostrado na Figura 2a. O copo metálico contendo o implante fixo ao cimento foi então inserido numa câmara acrílica com vedação, a qual foi completamente preenchida com solução de $0,90 \% \mathrm{NaCl}+$ água destilada (meio fisiológico artificial) e aerada pela recirculação da solução, conforme apresentado na Figura 2b. A temperatura da solução foi mantida em $37 \pm 1^{\circ} \mathrm{C}$, temperatura correspondente a do corpo humano.

O teste de fadiga do implante foi realizado utilizando uma máquina servohidráulica da marca Instron modelo 8872 , com célula de carga de $25,0 \mathrm{kN}$. Foi aplicado um carregamento senoidal compressivo com cargas mínima e máxima (aplicadas ao centro da cabeça femoral) de 0,300 a $3,330 \mathrm{kN}(\mathrm{R}=11)$, respectivamente, e frequência de $5,0 \mathrm{~Hz}$. O teste foi interrompido instantaneamente ao exceder a deflexão vertical máxima de $5,0 \mathrm{~mm}$, após cerca de 6 milhões de ciclos de carga concluídos, em decorrência da falha do implante por fadiga (Figura 2c). Outros detalhes sobre 0 aparato $e$ os procedimentos de teste podem ser encontrados nas normas ABNT citadas.
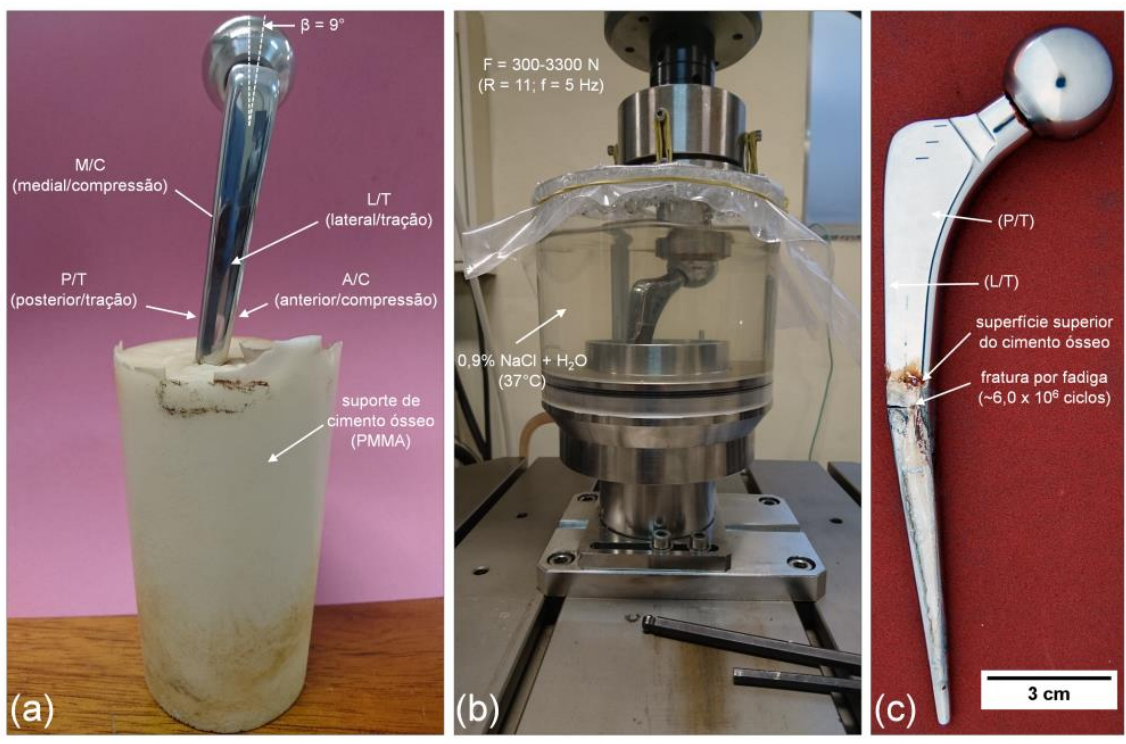

Figura 2. (a) implante de quadril embutido em cimento ósseo e identificação de suas partes, (b) teste de fadiga do implante em meio salino, (c) implante fraturado no teste de fadiga.

Em seguida, o implante foi removido do cimento ósseo e deformado por dobramento em temperatura ambiente $\left(\sim 26^{\circ} \mathrm{C}\right)$ até a ruptura completa na mesma máquina Instron, conforme mostrado na Figura 3. 


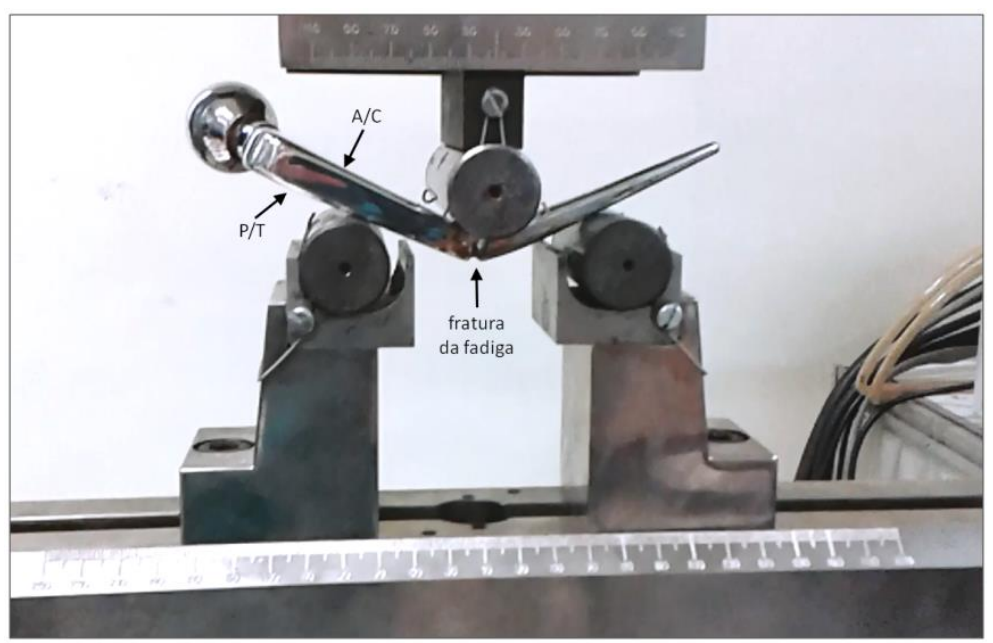

Figura 3. Dobramento do implante até a fratura completa.

Após o dobramento do implante, as superfícies de fratura superior e inferior foram extraídas para análise fractográfica utilizando a máquina de corte ATM Brillant 230. Para a análise da microestrutura na região logo abaixo da superfície de fratura, foi realizado um corte na direção diagonal desta superfície (a partir da região de nucleação da trinca de fadiga até a aresta oposta) utilizando a máquina de corte de precisão Buehler Isomet 1000. A superfície foi então preparada por metalografia tradicional, seguindo os passos de embutimento a quente $\left(\sim 150^{\circ} \mathrm{C}\right)$, lixamento e polimento. Em seguida, a amostra preparada foi aquecida com ar quente $\left(\sim 70^{\circ} \mathrm{C}\right) \mathrm{e}$ atacada quimicamente pela imersão em água régia $\left(10 \mathrm{ml} \mathrm{HNO}_{3} 65 \%+30 \mathrm{ml} \mathrm{HCl}\right.$ $37 \%)$.

A superfície de fratura foi fotografada num estereoscópio Olympus SZX16. As análises fractográficas e microestruturais foram realizadas utilizando o microscópio eletrônico de varredura (MEV) FEI Inspect S50 com filamento de tungstênio.

\section{RESULTADOS E DISCUSSÃO}

A falha do implante no teste de fadiga ocorreu a cerca de $6 \mathrm{~mm}$ abaixo da superfície superior do cimento (Figura 2c), provavelmente devido ao engaste mais efetivo, ou seja, menor movimentação do implante no interior do cimento, resultando em maior concentração de tensões nesta região. Este implante suportou mais ciclos de carregamento do que o estabelecido pela norma ABNT NBR ISO 7206-4 (5 milhões) e, embora ele não tenha atingido o número de ciclos recomendado pela norma ABNT NBR 15670-4 (10 milhões), não foi considerado reprovado pelos critérios desta norma porque foi testado com o modo de fixação no cimento estabelecido pela norma ABNT NBR ISO 7206-4 (com inclinação).

$\mathrm{Na}$ Figura 4 são mostradas as características da superfície de fratura e as regiões analisadas no MEV. É possível identificar na Figura $4 a$ a região de nucleação de trincas e ocorrência da falha por fadiga. Fica evidente na imagem que a falha teve início na aresta entre as faces lateral e posterior. Estas regiões estiveram submetidas a tensões de tração devido à flexão do implante durante a aplicação de carga (ver Figura 2a). De fato, a aresta pode ter atuado de modo a concentrar as tensões, favorecendo a ocorrência da falha por fadiga nesta região. Já a região próxima a aresta oposta (Figura 4a) apresentou aspecto de deformação plástica, ocasionado pelo dobramento do implante. A Figura 4b mostra as regiões analisadas ao longo do caminho de propagação das trincas de fadiga. Na Figura 5 
são mostradas ampliações de duas destas regiões, a Região 1 (Figura 5a), próxima a região de nucleação das trincas de fadiga, e a Região 6 (Figura 5b), próxima a região de deformação plástica.
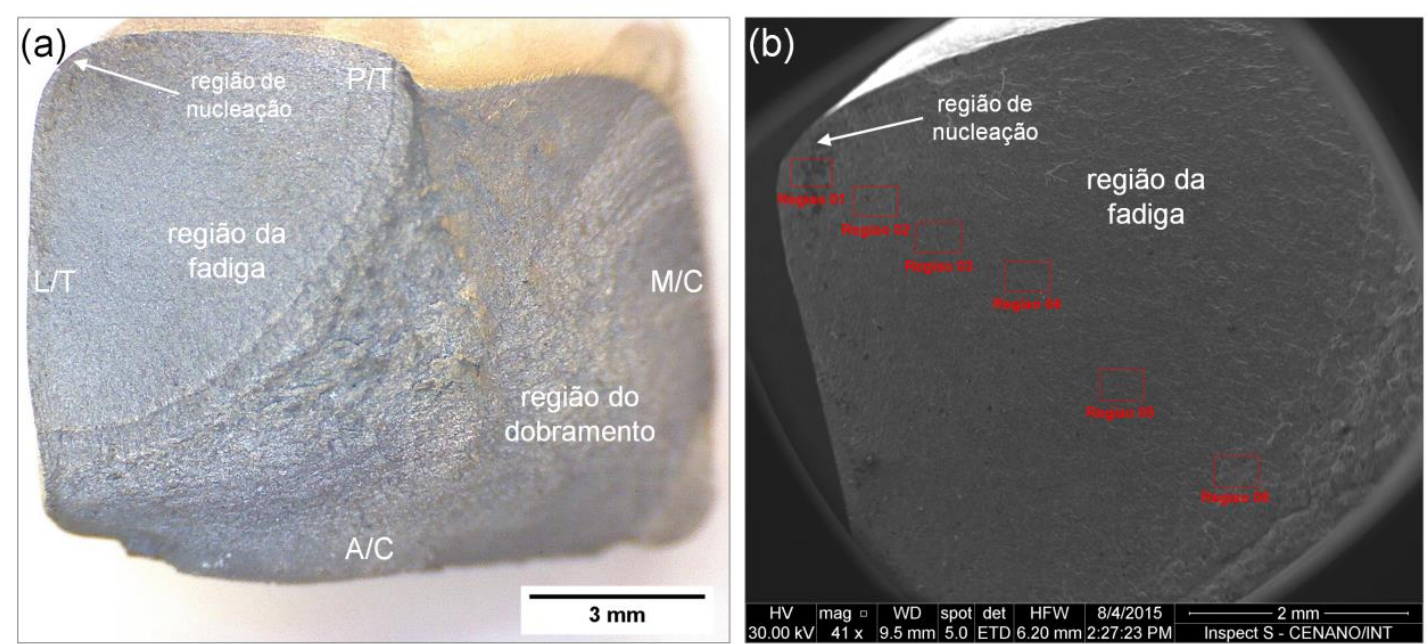

Figura 4. Superfície de fratura da haste: (a) indicação das partes e tensões na haste femoral (P/T posterior/tração, M/C - medial/compressão, A/C - anterior/compressão e L/T - lateral/tração), (b) MEV mostrando as regiões da fratura escolhidas para a análise fractográfica.

É possível observar na Figura 5 a estrias típicas de mecanismo de fadiga. Já na Figura 5b é possível observar alguns "dimples", que são característicos de deformação plástica. Esta é a região onde a propagação das trincas de fadiga foi interrompida e a fratura foi continuada no processo de dobramento.
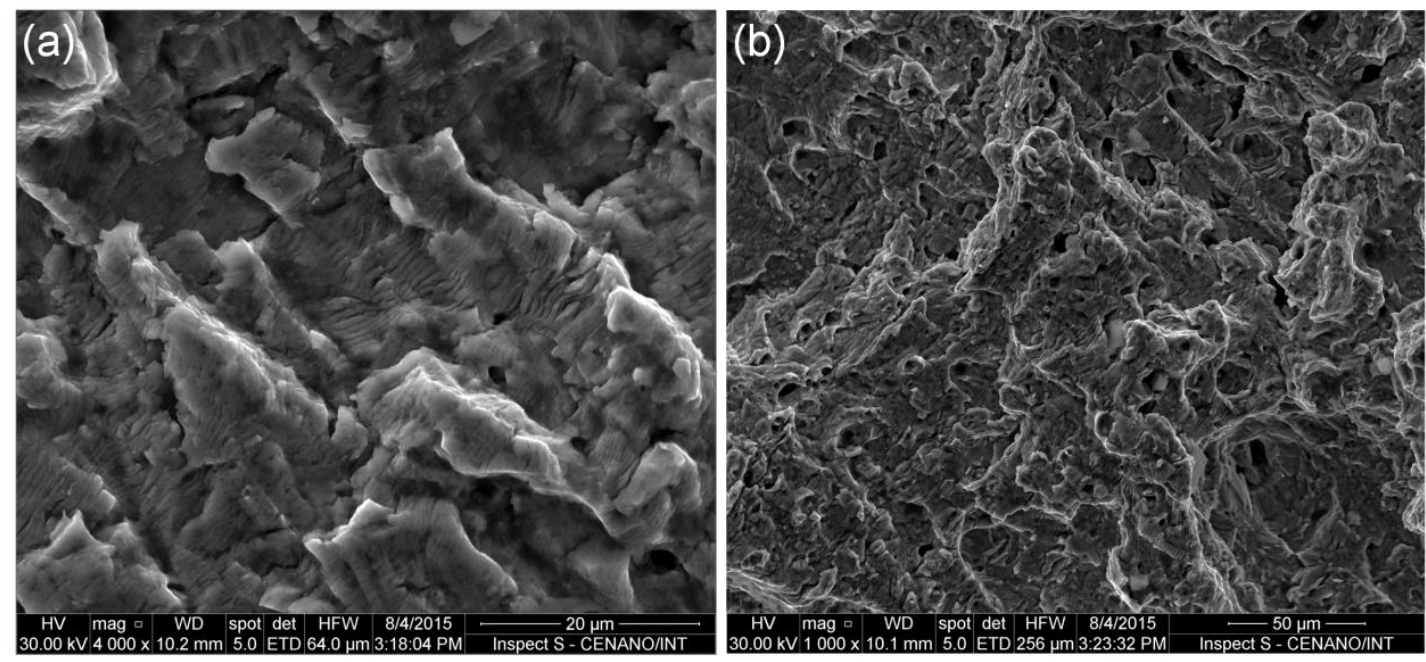

Figura 5. MEV da superfície de fratura nas Regiões 1 e 6 (ver Figura 4b): (a) Região 1 apresentando características de fratura por fadiga (estrias), (b) Região 6 indicando a ocorrência de deformação plástica ("dimples").

A Figura 6 mostra a microestrutura logo abaixo da superfície de fratura nas regiões de fadiga (Figura 6a) e dobramento (Figura 6b). A Figura 6a mostra que os precipitados de fase $Z$ se mantiveram intactos na região da fadiga, indicando que as condições de carregamento cíclico impostas ao material não foram suficientes para causar o rompimento ou decoesão dos precipitados. Além disso, por meio da análise da microestrutura da região de nucleação (imagem não mostrada) constatou-se que os precipitados não tiveram influência direta na nucleação das trincas de fadiga. Por 
outro lado, a Figura 6b mostra precipitados fraturados ou arrancados da matriz na região do dobramento. Este comportamento dos precipitados era esperado, tendo em vista o elevado grau de deformação ao qual esta região foi submetida.
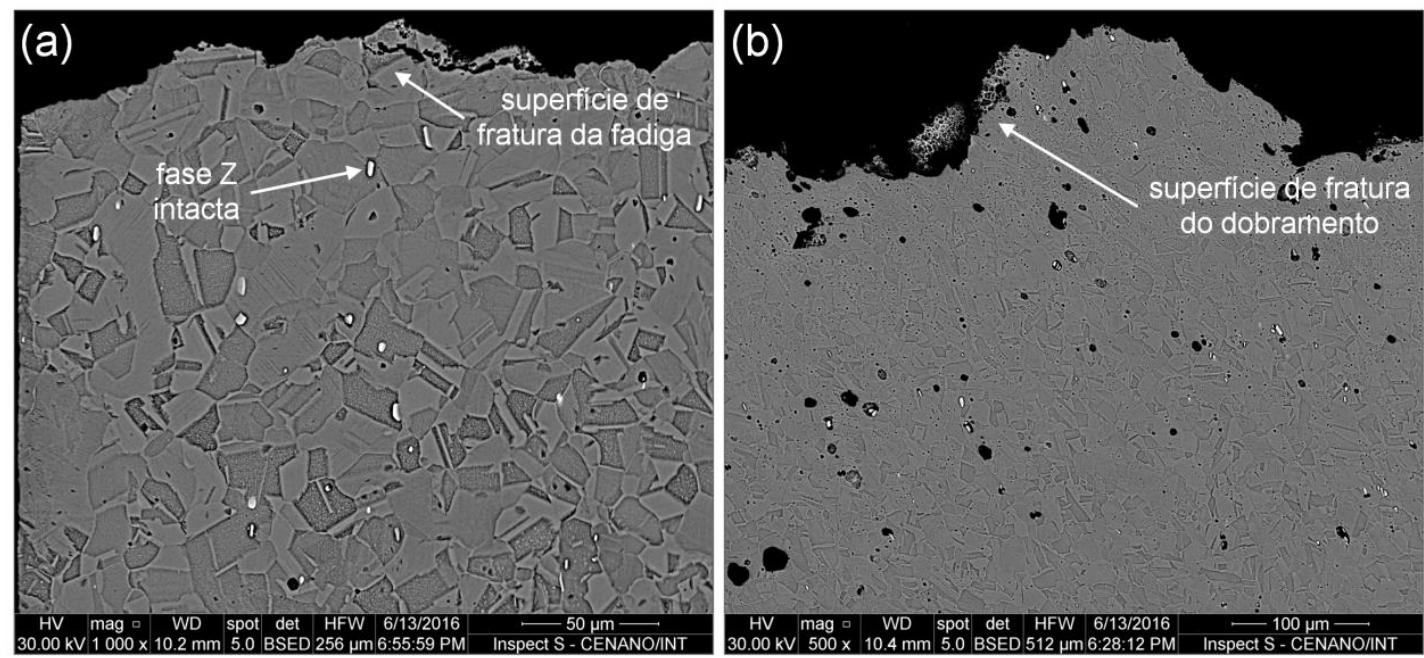

Figura 6. MEV da seção diagonal da fratura: (a) região logo abaixo da superfície de fratura gerada pelo teste de fadiga, mostrando os precipitados de fase Z preservados, (b) região logo abaixo da superfície de fratura do dobramento, mostrando os precipitados fragmentados e separados da matriz.

A Figura 7 mostra com mais detalhes alguns precipitados encontrados na região submetida à deformação plástica. Na Figura $7 \mathrm{a}$, a imagem de elétrons retroespalhados mostra que, mesmo com o elevado grau de deformação plástica, alguns precipitados permaneceram intactos, enquanto outros fraturaram e se descolaram da matriz. Os pontos escuros nas imagens são vazios ocasionados por precipitados fraturados e/ou descolados da matriz que foram removidos durante a preparação metalográfica. A Figura $7 \mathrm{~b}$ mostra, numa imagem de elétrons secundários, como ocorre a fratura e decoesão de um precipitado de fase $\mathrm{Z}$. Os vazios gerados ao redor dos precipitados provavelmente deram início ao processo que levou a ruptura completa do implante por deformação plástica no dobramento.
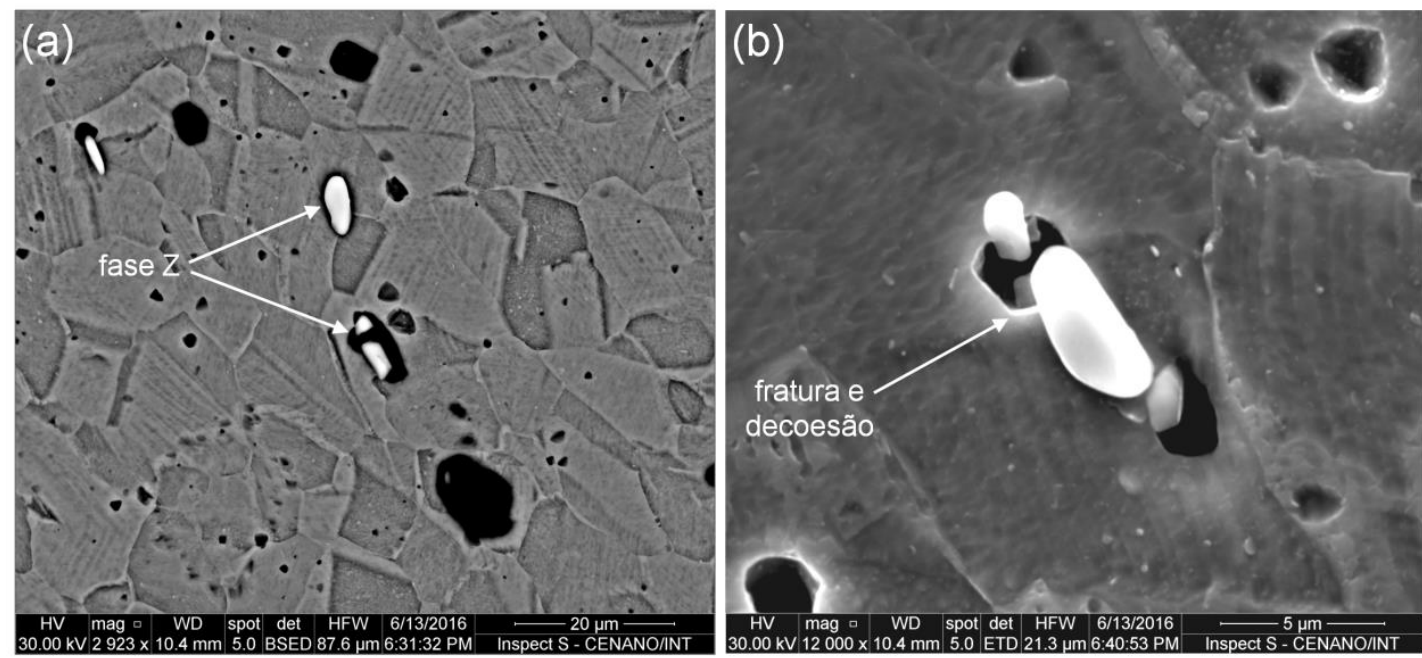

Figura 7. MEV da região submetida à deformação plástica por dobramento: (a) imagem do detector de elétrons retroespalhados (BSE) mostrando precipitado preservado e fraturado, (b) imagem do detector de elétrons secundários (SE) mostrando em detalhe a fratura e decoesão de um precipitado. 
Este resultado é semelhante ao reportado por Giordani et al. (7), que mostraram que os precipitados fraturaram quando este material foi submetido à fadiga com cargas de tração no regime plástico, atuando assim como sítios preferenciais para a nucleação de trincas.

No presente trabalho, não ficou provado que estes precipitados contribuem para a nucleação de trincas quando o carregamento encontra-se no regime elástico. Em outras palavras, não foi confirmado que os precipitados de fase $Z$ contribuem para a falha do aço inoxidável UNS S31675 quando este material é submetido à fadiga com deformação elástica. Portanto, os precipitados não se mostraram prejudiciais à qualidade mecânica do implante de quadril, tendo em vista que este trabalha no regime elástico, principalmente com cargas de compressão.

\section{CONCLUSÃO}

Os resultados mostraram a existência de estrias na superfície de fratura do implante, indicando que a fadiga foi o mecanismo de falha predominante. A análise microestrutural mostrou que os precipitados não fraturaram na região de falha por fadiga e não foram responsáveis diretos pela nucleação de trincas. Por outro lado, os precipitados sofreram fratura e decoesão na região submetida à deformação plástica por dobramento. Concluiu-se que, embora os precipitados sejam considerados sítios preferenciais para nucleação de trincas por fadiga no regime plástico, eles suportam carregamentos cíclicos no regime elástico e aparentemente não contribuem para a geração de trincas de fadiga, mesmo em condições teste mais severas do que aquelas recomendadas pelas normas técnicas específicas. Portanto, em termos de propriedades mecânicas, o aço inoxidável UNS S31675 mostrou-se adequado para uso em implantes de quadril.

\section{Agradecimentos}

Este trabalho foi financiado pelo Fundo Nacional da Saúde, auxílio no 25000.162216/2013-11TC 116/2013. O trabalho também recebeu apoio financeiro complementar da FAPERJ, FAPESC e CNPq. Os autores são gratos a Robson Centeno, Rafael Vinhosa e Rachel Pereira pelo apoio na preparação metalográfica e operação dos microscópios.

\section{REFERÊNCIAS}

1. Cubillos PO, dos Santos CT, Caminha IMV, de Jesus Monteiro M, de Oliveira Centeno R, dos Santos VO, et al. Chemical and Microstructural Characterization of Modular Femoral Stems Manufactured in ISO 5832-9 Stainless Steel. Metallogr Microstruct Anal [Internet]. 2017;6(1):44-54. Available from: http://link.springer.com/10.1007/s13632-016-0326-5

2. Grabke HJ. High Nitrogen Steels. The Role of Nitrogen in the Corrosion of Iron and Steels. ISIJ Int [Internet]. 1996;36(7):777-86. Available from: http://www.journalarchive.jst.go.jp/jnlpdf.php?cdjournal=isijinternational1989\&c dvol=36\&noissue $=7 \&$ startpage $=777$ \&lang $=$ en\&from $=$ jnlabstract

3. Ornhagen $\mathrm{C}$, Nilsson JO, Vannevik H. Characterization of a nitrogen-rich austenitic stainless steel used for osteosynthesis devices. J Biomed Mater Res [Internet]. 1996;31(1):97-103. Available from: http://www.ncbi.nlm.nih.gov/pubmed/8731154 
4. Windler M, Steger R. Mechanical and Corrosion Properties of Forged Hip Stems made of High-Nitrogen Stainless Steel. ASTM Int. 2003;(1):1-5.

5. Smethurst E. A new stainless steel alloy for surgical implants compared to 316 S12. Biomaterials. 1981;2(2):116-9.

6. Haraldsson C, Cowen S. Characterization of Sandvik Bioline High-N - A Comparison of Standard Grades F1314 and F1586. In: Stainless Steels for Medical and Surgical Applications [Internet]. 100 Barr Harbor Drive, PO Box C700, West Conshohocken, PA 19428-2959: ASTM International; 2003. p. 33-10. Available from: http://www.astm.org/doiLink.cgi?STP11149S

7. Giordani EJ, Guimarães VA, Pinto TB, Ferreira I. Effect of precipitates on the corrosion-fatigue crack initiation of ISO 5832-9 stainless steel biomaterial. Int J Fatigue [Internet]. 2004 Oct;26(10):1129-36. Available from:

http://linkinghub.elsevier.com/retrieve/pii/S014211230400057X

8. Giordano EJ, Alonso-Falleiros N, Ferreira I, Balancin O. Electrochemical behavior of two austenitic stainless steel biomaterials. Rem Rev Esc Minas [Internet]. 2010 Mar;63(1):159-66. Available from:

http://www.scielo.br/scielo.php?script=sci_arttext\&pid=S0370-

44672010000100027\&lng=en\&nrm=iso\&tIng=en 